\title{
Optimum Design of Shell and Tube Heat Exchangers using Modified Kinetic Gas Molecule Optimizer for the use of Low Temperature in Organic Rankine Cycles
}

\author{
Tallapureddy Subba Reddy, Thimmasandra Venkataswamy Sreerama Reddy
}

\begin{abstract}
Shell and Tube Heat Exchangers (STHEs) plays a crucial role in an effective design of Organic Rankine Cycle (ORC) power plants.The main aim of this research work is to design a cost-effective ORC in order to exploit low to medium temperature geothermal fluid or low grade industrial waste heat. In this research work, modified Kinetic Gas Molecule Optimization (KGMO) algorithm was developed forfinding the optimized parameter settings of the power plant. In modified KGMO algorithm, feedback learning stage was included for improving the fitness of individual worst particles. In addition, the proposed optimization algorithm was tested on two dissimilar fluids such asR245fa and R134a in order to show the effectiveness of proposed scheme. The experimental investigation showed that the proposed scheme effectively improved the heat exchanger performance as related to the existing schemes. The enhancement factor $J_{x}$ of proposed scheme was 2.8063 for R245fa fluid and 1.9346 for R134a fluid, which was better compared to the existing schemes; KGMO and Bell-Delaware method.
\end{abstract}

Key-words: Kinetic gas molecule optimization, organic rankine cycles, R134a, R245fa, and shell and tube heat exchanger.

\section{I.INTRODUCTION}

In recent times, world's electricity generation mainlybased onconventional fossil and nuclear energy sources. Majority of the electricity supply is generated from fossil fuels based thermal power plants using coal, oil and natural gas [1-2]. Presently, these energy sources are facing numerous issues like increasing prices, over dependence on fewer countries thosehave fossil fuel supplies, and concerns over change in climatic conditions [3]. As an outcome, the usage of renewable energy sources like solar, wind, etc are emerged as the potential alternatives [4]. In recent decades, the renewable energy generation systems like geothermal power plants are gaining importance due to the environmental issues and limited resources. The amount of energy stored in the low-temperature geothermal heat sources is high and the conversion to electricity is inefficient due to the low temperature [5-8]. Several researcheshas been done for maximizing the conversion efficiency by the use of ORC [9].

\footnotetext{
Revised Manuscript Received on February 05, 2020.

* Correspondence Author

T Subba Reddy, Professor, Department of Mechanical Engineering Bangalore, Institute of Technology, Bangalore.

T V Sreerama Reddy, Professor, Department of Mechanical Engineering Bangalore, Institute of Technology, Bangalore.
}

(C) The Authors. Published by Blue Eyes Intelligence Engineering and Sciences Publication (BEIESP). This is an open access article under the CC BY-NC-ND license (http://creativecommons.org/licenses/by-nc-nd/4.0/)
The STHEs is combined with ORC for preventing liquid flow inside the tubes to mix with the fluids outside the tubes. Many research works are done to improve the electricity production efficiency in ORCs by optimizing the cycle parameters like pressures, temperatures and mass flow rates [10-11]. Recently, several systems are developed in STHEs to improve the electricity production efficiency such asentransy theory with genetic algorithm [12], genetic algorithm [13-14], non-dominated sorting genetic algorithm [15].However, the existing algorithms have a few own limitations like heat-source cooling efficiency is limited and the amount of heat losses from the outer surface of the heat exchanger to the surroundings is excess.In order to address the above-mentioned problems, an efficient technique is developed for electricity generation from the combined ORCs and STHEs. In this research paper, a new optimization technique (modified-KGMO) was developed in order to find the parameters for an effective heat transfer system. A new feedback learning phase was included in the conventional KGMO algorithmto easily find the local optima and to improve the accuracy of solution. In this work, R245fa and R134a fluids were used, because of its eco-friendly features. In addition, the parameters like, inlet pressure, inlet temperature, outlet temperature, outlet pressure, mass flow, etc were considered to attain better optimization. The experimental study showed that the proposed optimization algorithm delivered better performance in heat exchanger related to other existing algorithms.

This research paper is pre-arranged as follows. In section 2, numerous research papers on optimization of STHEs design in ORC system are reviewed. Detailed explanation about the proposed system is given in section 3. In addition, section 4 illustrates about the quantitative analysis and comparative analysis of the proposed system. The conclusion is made in section 5 .

\section{II.LITERATURE REVIEW}

Many methodologies are developed by the researchers in optimization of STHEs design in ORC system. In this literature section, a brief review of some important contributions to the existing literature is presented.

I. Milcheva, et al, [16] developed a new algorithm (BellDelaware method) to regulate the calculation approaches for the main geometrical parameters like leakage areas, tubes in the overlapping region and cross flow area.

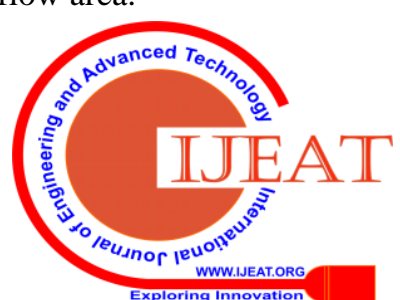


In experimental section, the developed method showed a better agreement with operational data. In this research study, the developed method used a new enhancement factor $J x$, which was applicable to other STHEs with double segmental baffles. Additionally, the developed method plays a crucial role in dynamic simulation of the geothermal ORCssystem. Other working fluids and dissimilar operational conditions were not used for examining the applicability of the adapted correlation to other STHEs with double segmental baffles.

A. Erdogan, et al, [17] analysed the design of STHEs, which was utilized to combine ORC based geothermal power plant and parabolic trough solar collectors. In this research work, parametric studies were conducted for identifying the effect of key design parameters on the output parameters of the model like pumping power and the heat exchanger surface area. Then, a thermal model (two-stage taguchi methodology) was utilized to identify the temperature of thermal oil, whichenters into the heat exchanger under dissimilar solar irradiation intensity. The developed two-stage taguchi schemedelivered better irradiation intensity, and heat transfer surface area. A few comprehensive thermal model includes two issues; pressure drop within the tube side of the heat exchanger and excessive heat loss.

D. Walraven, et al, [18] analysed the system optimization of dissimilar configurations of ORCs with both STHEs and plate heat exchangers. The main objective of this research paper was to design ORCs by performing system optimization. The developed systemshown that the effectiveness of ORC enhances with increasing in heatexchanger surface. Each fluidincludes a heat-source inlet temperature from which the plant efficiency was maximized. Reclaimed ORCs were suitable only when the heat-source outlet temperature was inhibited. Respectively, the best double subcritical ORCs performed effectively compared to the best single-pressure transcritical cycles. One main disadvantage of plate heat exchangers was that the geometry of both sides weresimilar, which resulted in an inefficient heat exchanger.

D. Walraven, et al, [19] analysed system optimization of dissimilar configurations of ORCs with STHEs. Initially, system optimization of ORCs was done by optimizing the cycle parameters with the configurations of STHEs. So, each heat exchanger has optimal allocation of pinch point temperature, heat exchanger surface and pressure drop. From the experimental analysis, it was identified that the sixty tube configurations were required for two phase heat exchanger and thirty tube configurations for single phase heat exchangers. By includingsecond pressure level, the performance of sub-critical cycles were strongly improved. In most of the circumstances, the heatsource cooling efficiency was lowdue to the constraint in heat-source outlet temperature.

S. Lakhani, et al, [20] developed an integrated model as multitube shell and tubeLatent Heat Thermal Energy Storage System (LHTE). The developed method found that LHTE with lower overall diameter and longer length delivered better performance in solar thermal power plant compared to the storage system with larger diameter and shorter length. In LHTE system, maximum melt fraction

was achieved with lowest overall diameter. The pressure drop was high for LHTES system with lower overall diameter and longer length. In addition, the discharging efficiency of LHTES system was highly affected, which was found to be maximum for the lower overall diameter of storage system.

T.S. Reddy, T.V.S. Reddy, [21] developed an optimizer (KGMO) for identifying the optimized parameter settings for the power plant. In this research study, STHEs with a double segmented baffle was examined for single phase flow model. The performance of developed technique was evaluating with two dissimilar fluids such as R245fa and R134a. The developed methodology effectively finds the global minima and also showed high efficiency related to the existing methods. The conventional KGMO algorithm includes a few drawbacks like easily sticks in the local optima and accuracy of solution was low, when applied to high dimensional and complex objective functions.

In order to overcome the above-mentioned problems, a new optimization methodology is included in the ORCsfor improving the thermal efficiency of heat exchanger.

\section{PROPOSED METHODOLOGY}

The heat exchanger equipment plays a crucial role in developing an effective design of ORC power plants. Generally, the design of STHEs in ORC systems depends on numerous aspects such as material selection, phase state of the working fluid, and the type of construction or optimization of geometrical parameters. The objective of optimization is to find the system configuration, which helps to maximizes the mechanical work output for a given heat source. In this research work, modified KGMO scheme is used to obtain higher thermal efficiency. In addition, the heat exchanger model is designed by using the cell models by adjusting the factors like heat transfer information, pressure drop, and geometry parameters. Eachcell models states control volumes that consists of discretized equations for material and energy balance. In this work, three cell types (refrigerant, liquid, and wall calls) are considered for simulating the pre-heater. Then, the pressure drop and heat transfer area are assigned to each refrigerant and liquid cells. In this context, the Gnielinski correlation implemented for the tube-side heat transfer coefficients. The shell-side heat transfer coefficient for each refrigerant cell fluids (R245fa and R134a) are measured using modified KMGO algorithm. The pressure drop from cold and hot fluid cells are assigned as input parameters from the measured data. The modified KMGO algorithm measures the accuracy of heat transfer correlation for the shell side.

\subsection{Tube side heat transfer coefficient}

The tubes Reynolds number $R_{e D}$ should be higher than $10^{4}$ for the considered load conditions. So, a fully developed turbulent flow is occurred as shown in the table 2 . In order to develop turbulent flow, the tube side heat exchanger correlation is considered on the basis of equation (1). 
$N u_{t}=\left\{\frac{\left(\frac{f}{8}\right) R e_{D} P r}{\left.1+12.7\left(\frac{f}{8}\right)^{\frac{1}{2}\left(\frac{2}{3}\right.} \operatorname{Pr}-1\right)}\right\}\left\{1+\left(\frac{d_{i n}}{L}\right)^{\frac{2}{3}}\right\}\left(\frac{p r_{t}}{p r_{t w}}\right)^{0.11} \times$
$R e_{D} \geq 10^{4}(1)$

Where, $D$ is denoted as diameter, $R e$ is indicated as Reynolds number, and $\mathrm{Pr}$ is represented as Prandtl number. The friction factor $f$ is attained utilizing the correlation of Konakov that is mathematically denoted in equation (2). Table 2 represents the heat transfer coefficient and Reynolds's number of STHEs.

$f=\left(1.8 \log _{10} R e_{D}-1.5\right)^{-2} 10^{4} \leq R e_{D} \leq 10^{6}$

\subsection{Shell side heat transfer coefficient}

In this research study, bell Delaware approach is utilized to calculate the average shell side heat transfer coefficient. The general formula of bell Delaware approach is denoted in the equation (3).

$h_{s}=J_{c} J_{l} J_{r} J_{b} J_{s} J_{i}(3)$

The bell Delaware approach considers several effects into account that diminishes the ideal heat transfer coefficient $h_{i}$ on a tube bank in cross flow. The variations in the ideal cross flow regime is considered in the form of many correction factors such as $J_{c}, J_{l}, J_{r}, J_{b}, J_{s}$. Table 1 denotes the effects and correction factors. The ideal heat transfer coefficient $h_{i}$ is identified by using the equation (4).

$$
h_{i}=\frac{j_{i} c_{p s} G_{s}\left(\varphi_{s}\right)^{n}}{p r_{s}^{2 / 3}}
$$

Table 1. Correction Factors (CF) of bell Delaware approach

\begin{tabular}{|l|l|}
\hline CF & Influences or effects \\
\hline Baffle cut CF $U_{c}$ ) & Effect of baffle cut window \\
\hline Unequal baffle spacing CF $\left.U_{s}\right)$ & $\begin{array}{l}\text { Effect of inadequate outlet or inlet baffle spacing is totally differ from central } \\
\text { baffle spacing }\end{array}$ \\
\hline Bundle bypass CF $\left.U_{b}\right)$ & $\begin{array}{l}\text { Effect of flow between tube bundle and inner shell wall that influences the pass } \\
\text { partition lanes }\end{array}$ \\
\hline Laminar flow CF $\left(J_{r}\right)$ & $\begin{array}{l}\text { Effect of flow between tube bundle and inner shell wall that influences the pass } \\
\text { partition lanes }\end{array}$ \\
\hline Baffle leakage CF $\left(U_{l}\right)$ & Effect of leakages between baffles and shell, and between baffles and tubes \\
\hline
\end{tabular}

The bell-Delaware approach does not change the basic equation structure. The adaption of bell-Delaware approach is based on the estimation of tube numbers and characteristic areas. The principle of bell-Delaware approach is detailed in the sections 3.2.1, 3.2.2and 3.2.3.

\subsubsection{Shell Side Cross Flow Area (SSCFA)}

Initially, a division of the flow in equal shares for window left and right is assumed due to the symmetry of heat exchanger. Therefore, the SSCFA $S_{m}$ is the sum of right and left cross flow areas $S_{m, l}$ and $S_{m, r}$. Henceforth, the SSCFA is evaluated using the equation (5).

$S_{m}=S_{m, l}+S_{m, r}=L_{b c}\left(b x-N_{t c f} d\right) .2$

Central baffle spacing $L_{b c}$ is multiplied with the cross flow region width for obtaining half SSCFAs $S_{m, l}$ or $S_{m, r}$. Then,subtract the tube width $N_{t c f} \times d$ from the entire width $b x$. At last, the product is doubled for obtaining the entire SSCFA $S_{m}$.

\subsubsection{Effective tube row number}

In order to obtain the total tube row number in cross flow $N_{t c c}$, the number of tube rows in the overlapping regions $N_{t c c, l}$ and $N_{t c c, r}$ are combined as represented in the equation (6). Respectively, the tube numbers of right and left wing windows $N_{t w, l}$ and $N_{t w, r}$ are combined in order to determine the wing window tube numbers $N_{t w, w}$ as given in the equation (7).

$N_{t c c}=N_{t c c, l}+N_{t c c, r}(6)$

$N_{t w, w}=N_{t w, l}+N_{t w, r}(7)$

\subsubsection{Adaption of input parameters based on average values}

The central and wing baffle has dissimilar geometrical dimensions like the number of tubes in the baffle window.
Thus, the average window tube number is evaluated by considering the right- and left-wing windows as shown in the equations (8) and (9).

$$
\begin{aligned}
& N_{t w}^{\text {aver }}=0.5\left(N_{t w, w}+N_{t w, c}\right) \\
& F_{w}=\frac{N_{t w}^{a v e r}}{N_{t}}
\end{aligned}
$$

Where, $F_{w}$ is denoted as the fraction of baffle window tube, which is evaluated by categorizing the average window tube number by the total tube number $N_{i}$. The similar applies in the tube-to-baffle and shell-to-baffle leakage areas are calculated by using the equations (10) and (11).

$S_{s b}^{a v e r}=0.5\left(S_{s b, w b, l}+S_{s b, w b, r}+S_{s b, c b}\right)$

$S_{t b}^{a v e r}=0.5\left(S_{t b, w b, l}+S_{t b, w b, r}+S_{t b, c b}\right)$

\subsection{Multi-objective optimization using modified KGMO algorithm}

In this research study, the multi-objective optimization minimizes the heat transfer area and pumping power in the STHEs. The low values of pumping power and area are desired to decrease the operating and capital costs. These objectives are accomplished by using modified KGMO algorithm. In the developed algorithm, the gas molecules are considered as the agents in the search space. In KGMO algorithm, every gas molecule has four characteristics such as kinetic energy, position, mass, and velocity. In each gas molecule, the kinetic energy identifies its position and velocity. In KGMO algorithm, the gas molecules explore the entire search for identifying the point that has the lowest temperature. Then, consider a system that has $N$ agents (gas molecules) and find the position and velocity of the $i^{\text {th }}$ agent using the equations (12) and (13). 
$X_{i}=\left(x_{i}^{1}, \ldots . x_{i}^{d}, \ldots . x_{i}^{n}\right), i=1,2, \ldots . N$

$(12)$

$V_{i}=\left(v_{i}^{1}, \ldots . v_{i}^{d}, \ldots . v_{i}^{n}\right), i=1,2, \ldots . N$

Where, $x_{i}^{d}$ and $v_{i}^{d}$ are denoted as the position and velocity of the $i^{\text {th }}$ agent in the $d^{\text {th }}$ dimension.

In cylinder, the movement of the gas molecule depends on the Boltzmann distribution. In

which, the velocity of the gas molecules is inversely proportional to the kinetic energy of the molecule. Mathematically, the kinetic energy is defined in the equation (14).

$$
k_{i}^{d}(t)=\frac{3}{2} N b T_{i}^{d}(t), K_{i}=\left(k_{i}^{1}, \ldots . k_{i}^{d}, \ldots . k_{i}^{n}\right),
$$

$i=1,2, \ldots . N(14)$

Where, $T_{i}^{d}(t)$ is stated as temperature, $N$ is indicated as number of gas molecules, and $b$ is represented as Boltzmann constant. The velcity of updated molecule is given in the equations (15) and (16).

$v_{i}^{d}(t+1)=T_{i}^{d}(t) w v_{i}^{d}(t)+C_{1} \operatorname{rand}_{i}(t)\left(\right.$ gbest $^{d}-$

$\left.X_{i}^{d}(t)\right)+C_{2} \operatorname{rand}_{i}(t)\left(\right.$ pbest $\left._{i}^{d}-X_{i}^{d}(t)\right)$

$T_{i}^{d}(t)=0.95 \times T_{i}^{d}(t-1)(16)$

The vector $g_{\text {best }}=\left(\right.$ gbest $^{1}$, gbest $^{2},$. gbest $\left.^{n}\right)$ is represented as the prior best position among all the molecules and the $p_{\text {best }}=\left(\right.$ pbest $_{i}^{1}$, pbest $_{i}^{2},$. pbest $\left._{i}^{n}\right)$ is denoted as the prior best position in the $i^{t h}$ gas molecule. In this research study, $\left[-v_{\min }, v_{\max }\right]$ is utilized as the limits of gas molecular velocity. If $\left|v_{i}\right|>v_{\max }$, then $\left|v_{i}\right|=v_{\max }, w$ is denoted as the inertia weight that reflects the gas molecules resistance in order to slow the movement and $\operatorname{rand}_{i}(t)$ is indicated as the uniform random variable, which ranges between [0,1], $C_{1}$ and $C_{2}$ are stated as two acceleration constants.The mass $m$ of every gas molecule is a random number, which ranges from $0<m \leq 1$. The random number simulates dissimilar types of gases in dissimilar executions of the algorithm. On the basis of motion in physics, the position of the molecule is determined using the equations (17) and (18).

$$
\begin{aligned}
& x_{t+1}^{i}=\frac{1}{2} a_{i}^{d}(t+1) t^{2}+v_{i}^{d}(t+1) t+x_{i}^{d}(t)(17) \\
& a_{i}^{d}=\frac{\left(d v_{i}^{d}\right)}{d t}, d v_{i}^{d}=\sqrt{\frac{2\left(d k_{i}^{d}\right)}{m}}
\end{aligned}
$$

In the time interval $\Delta t$, equation (18) is rewritten as equation (19).

$$
a_{i}^{d}=\frac{\sqrt{\frac{2\left(\Delta k_{i}^{d}\right)}{m}}}{\Delta t}
$$

Then, from the equations (17) and (19), the position of the molecule is calculated as given in equations (20) and (21)

$$
\begin{aligned}
& x_{t+1}^{i}=\frac{1}{2} a_{i}^{d}(t+1) \Delta t^{2}+v_{i}^{d}(t+1) \Delta t+x_{i}^{d}(t) \\
& x_{t+1}^{i}=\frac{1}{2} \sqrt{\frac{2\left(\Delta k_{i}^{d}\right)}{m}}(t+1) \Delta t^{2}+v_{i}^{d}(t+1) \Delta t+x_{i}^{d}(t)
\end{aligned}
$$

Finally, the minimum fitness is determined by using the equations (22) and (23),

$$
\begin{aligned}
& \text { pbest }_{i}=f\left(x_{i}\right), \text { if } f\left(x_{i}\right)<f\left(\text { pbest }_{i}\right)(22) \\
& \text { gbest }=f\left(x_{i}\right), \text { if } f\left(x_{i}\right)<f(\text { gbest })
\end{aligned}
$$

The conventional KGMO algorithm includes a few drawbacks like easily sticks in the local optima and accuracy of solution is lower, when applied to high dimensional and complex objective functions. To address this problem, a new feedback learning phase is included in the conventional KGMO algorithm. The feedback learning stage improves the fitness of individualpworst. The fitness of individual in pworst is lower and has a larger difference between any two individuals, so the diversity of pworst is larger. In addition, the individuals in pworst upgrades the fitness using feedback learning from the pbest as denoted in the equation (24).

Feedback learning $=\frac{\mathrm{f}\left(\mathrm{X}_{\mathrm{i}}\right)}{\text { diversity of pworst }}$

\subsubsection{Pseudo code of modified KGMO algorithm}

For every gas molecule \{

Initialize the gas molecules, until satisfying all constraints

\}

Do \{

For every particle \{

Evaluate fitness value

If the evaluated fitness value is better, set present value as the new pbest.

$$
\text { \} }
$$

\}

For every particle \{

If the evaluated pbest is better then consider it as gbest or no existing gbest

\}

Determine the kinetic energy for each gas molecule using equation (14)

Update particle velocity and position using the equations (15), and (21)

Apply feedback learning to improve the fitness of pworst using equation (24)

\}

\} when the minimum error or maximum iteration is not achieved.

\section{IV.EXPERIMENTAL RESULT AND DISCUSSION}

In this research, MATLAB (version 2018a) was used for experimental simulation with Intel ${ }^{\circledR}$ core $^{\mathrm{TM}} \mathrm{i} 3-7100 \mathrm{U}, 4 \mathrm{~GB}$ RAM, 64-bit OS, and x-64 based processor. In order to estimate the effectiveness of proposed system, the performance of proposed system was compared with the existing systems: Bell-Delaware method [16] andKGMO [21]. 
The performance of the proposed algorithm is evaluated in light ofinlet temperature, outlet temperature, inlet pressure, outlet pressure, mass flow, geothermal water inlet and outlet temperature, thermal water mass flow, and relative deviation geothermal fluid outlet temperature under two different fluids such asR245fa fluid and R134a fluid. The parameters of heat transfer coefficients and Reynolds numbers of shell and tube side is denoted in table 2 .

Table 2. Heat transfer coefficients and Reynolds numbers of shell and tube side

\begin{tabular}{|c|c|c|c|c|c|c|c|c|c|}
\hline & $\alpha_{s s, \min }$ & $\alpha_{s s, \max }$ & $\boldsymbol{R} \boldsymbol{e}_{s, \min }$ & $\boldsymbol{R} \boldsymbol{e}_{s, \max }$ & $\alpha_{t s, \min }$ & $\alpha_{t s, \max }$ & $R e_{t, \min }$ & $\boldsymbol{R} \boldsymbol{e}_{t, \max }$ & $\frac{\alpha_{t s, \text { max }}}{\alpha_{s s, \text { max }}}$ \\
\hline Unit & $(\mathrm{W} / \mathrm{m} 2 \mathrm{~K})$ & $(\mathrm{W} / \mathrm{m} 2 \mathrm{~K})$ & - & - & $(\mathrm{W} / \mathrm{m} 2 \mathrm{~K})$ & $(\mathrm{W} / \mathrm{m} 2 \mathrm{~K})$ & - & - & - \\
\hline Design & 1204 & 1219 & 63743 & 73544 & 14058 & 14245 & 113728 & 118501 & 11.68 \\
\hline
\end{tabular}

\subsection{Quantitative analysis using R245fa fluid}

The transient behaviour of STHEs with baffles is a prime concern in many industrial applications. The performance of STHEs units depends on the number of passes for both shell and tube-side fluids by the arrangements of inlet and outlet connections among other factors.The modeling technique employed to divide the heat exchangers into a number of lumped elements called cells, where heat transfer operation takes place. The resulting model visualized as a cell network, where the connection pattern is defined by the general structure of the heat exchanger to be simulated.In this section, the ORC working fluid (R245fa) is considered as the geo-thermal fluid for preheating the fluid, which is close to the saturation temperature. Then, the working fluid is evaporated that is called as high temperature evaporator. The operational parameters of ORC working fluid (R245fa) are denoted in table 3 . The validation outcome shows that the proposed algorithm (modified KGMO) gives better result related to the existing algorithms (KGMO [21], and Bell-Delaware method [16]). For instance, the enhancement factor $J_{x}$ of modified KGMO is 2.8063, which is better related to the existing algorithms (KGMO is 1.8864, and Bell-Delaware method is 1.51). The graphical depiction of simulation result of preheater using R245fa fluid is denoted in figure 1.

Table 1. Simulation result of preheated using $\mathbf{R} 245 \mathrm{fa}$ fluid

\begin{tabular}{|l|l|l|l|l|}
\hline Operating point & Unit & Bell-Delaware method [16] & KGMO [21] & $\begin{array}{l}\text { Modified } \\
\text { KGMO }\end{array}$ \\
\hline Enhancement factor $J_{x}$ & - & 1.51 & 1.8864 & 2.8063 \\
\hline R245fa inlet temperature & ${ }^{\circ} \mathrm{C}$ & 19.9 & 19.9000 & 19.900 \\
\hline R245fa outlet temperature & ${ }^{\circ} \mathrm{C}$ & 59.34 & 64.5239 & 64.2804 \\
\hline R245fa inlet pressure & $\mathrm{bar}$ & 5.48 & 5.4800 & 5.4800 \\
\hline R245fa outlet pressure & $\mathrm{bar}$ & 5.18 & 4.3800 & 4.3800 \\
\hline R245fa mass flow & $\mathrm{kg} / \mathrm{s}$ & 85.55 & 88.3333 & 88.3333 \\
\hline Geothermal water inlet temperature & ${ }^{\circ} \mathrm{C}$ & 66.64 & 66.6400 & 66.6400 \\
\hline Geothermal water outlet temperature & ${ }^{\circ} \mathrm{C}$ & 47.77 & 52.1439 & 51.9004 \\
\hline Geothermal water inlet pressure & bar & 15 & 15 & 15 \\
\hline Geothermal water outlet pressure & $\mathrm{bar}$ & 15 & 4.3800 & 4.3800 \\
\hline Thermal water mass flow & $\mathrm{kg} / \mathrm{s}$ & 58.1 & 61.1839 & 60.9404 \\
\hline Relative deviation R245fa outlet temperature & $\%$ & 0.38 & 0.3214 & 0.3214 \\
\hline Relative deviation geothermal fluid outlet temperature & $\%$ & -0.19 & -0.1400 & -0.1400 \\
\hline
\end{tabular}


Optimum Design of Shell and Tube Heat Exchangers using Modified Kinetic Gas Molecule Optimizer for the use of Low Temperature in Organic Rankine Cycles

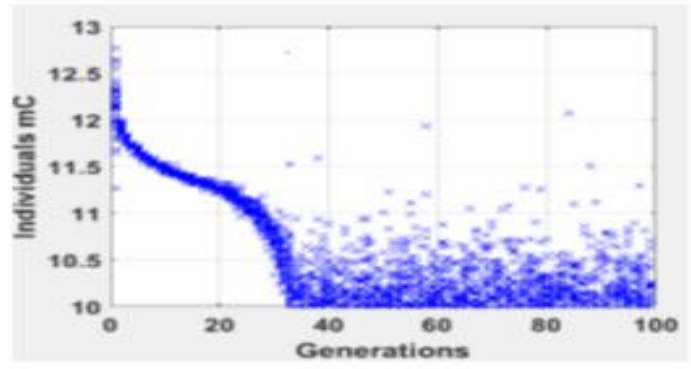

(A)

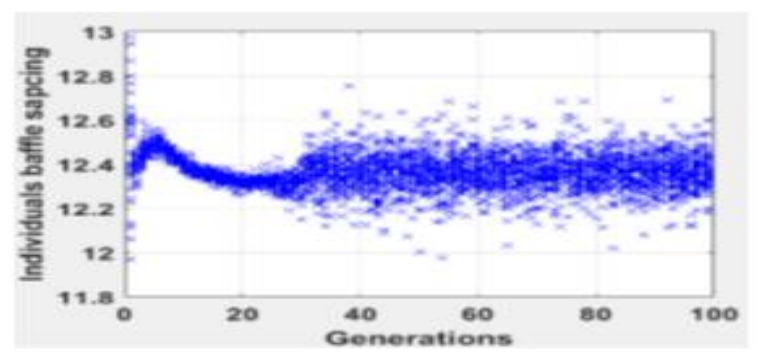

$(\mathbf{C})$

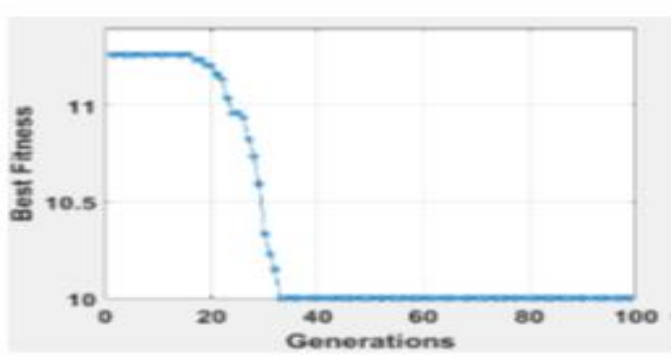

(B)

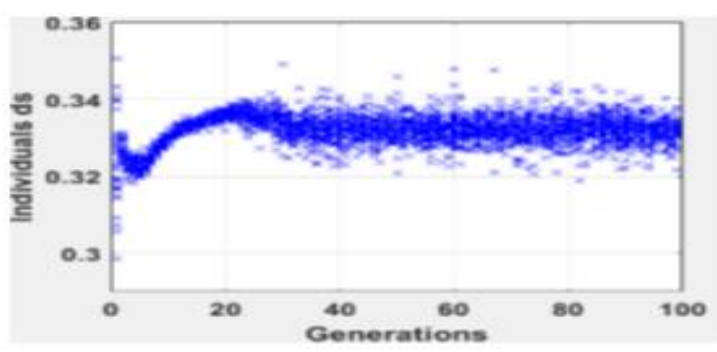

(D)

Figure 1. a) Generation of individuals $\mathrm{mC}$, b) Generation of individual baffle spacing, c) generation of best fitness, d) Generation of individual ds for R245fa fluid

\subsection{Quantitative analysis using R134a fluid}

In this segment, the ORC working fluid (R134a) is considered as the geo-thermal fluid to preheat the fluid that is closer to the saturation temperature. The operational parameters of ORC working fluid (R134a) are denoted in table 4. As R245fa fluid, the experimental result shows that the proposed algorithm (modified KGMO) gives better result related to the existing algorithm (KGMO [21]). For example, the enhancement factor $J_{x}$ of modified KGMO is 1.9346, which is better related to the existing algorithms (KGMO is 1.2329). The graphical depiction of simulation results of preheater using R134afluid is denoted in figure 2.The enhancement factor $J_{x}$ is developed linearly by using the shell fluid mass flow rate $M_{s}$, which is mathematically given in equation (25)

$J_{x}=0.0058 . M_{s}+1.0102$

Table 2. Simulation result for the LT preheater using R134a fluid

\begin{tabular}{|l|l|l|l|}
\hline Operating point & Unit & KGMO [21] & Modified KGMO \\
\hline Enhancement factor $J_{x}$ & - & 1.2329 & 1.9346 \\
\hline R134a inlet temperature & ${ }^{\circ} \mathrm{C}$ & 19.9000 & 19.9000 \\
\hline R134a outlet temperature & ${ }^{\circ} \mathrm{C}$ & 42.1741 & 44.3508 \\
\hline R134a inlet pressure & Bar & 5.4800 & 5.4800 \\
\hline R134a outlet pressure & Bar & 6.5800 & 6.5800 \\
\hline R134a mass flow & $\mathrm{kg} / \mathrm{s}$ & 67.0000 & 67.0000 \\
\hline Geothermal water inlet temperature & ${ }^{\circ} \mathrm{C}$ & 66.6400 & 66.6400 \\
\hline Geothermal water outlet temperature & ${ }^{\circ} \mathrm{C}$ & 27.5941 & 29.7708 \\
\hline Geothermal water inlet pressure & $\mathrm{Bar}$ & 15.0000 & 15.0000 \\
\hline Geothermal water outlet pressure & $\mathrm{Bar}$ & 17.3000 & 17.3000 \\
\hline Thermal water mass flow & $\mathrm{kg} / \mathrm{s}$ & 38.3141 & 40.4908 \\
\hline Relative deviation R134a outlet temperature & $\%$ & 0.4032 & 0.4032 \\
\hline $\begin{array}{l}\text { Relative deviation geothermal fluid outlet } \\
\text { temperature }\end{array}$ & $\%$ & -0.2600 & -0.2600 \\
\hline
\end{tabular}




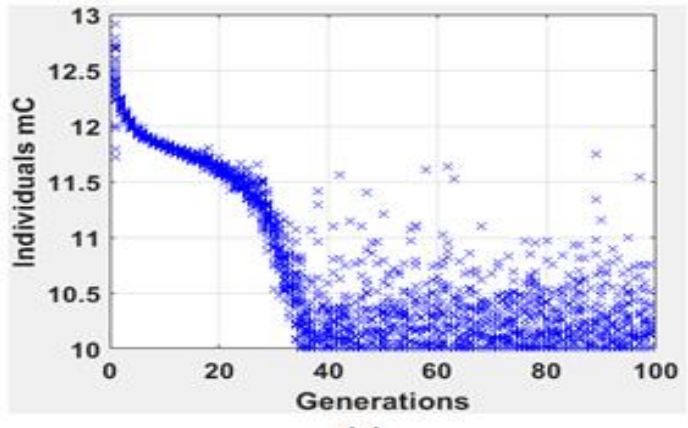

(a)

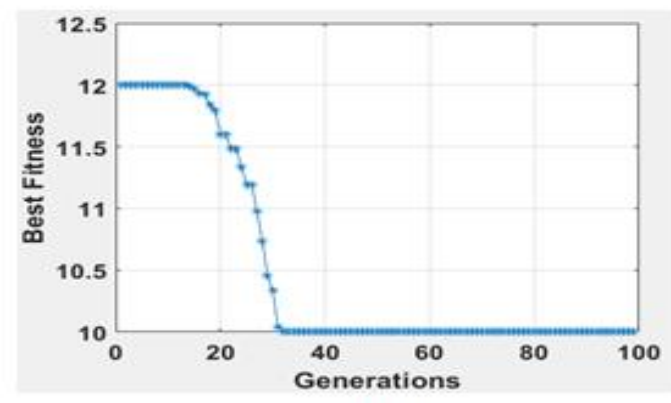

(C)

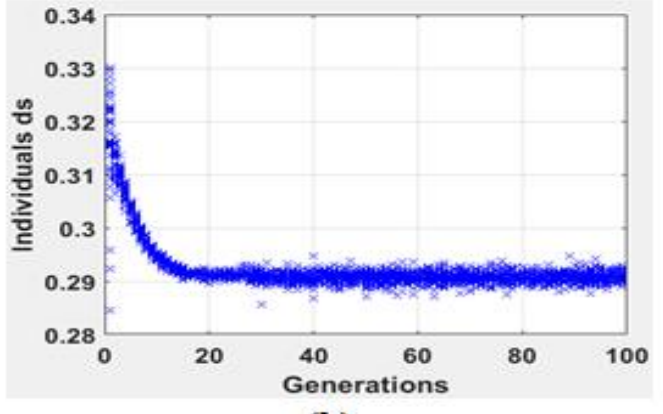

(b)

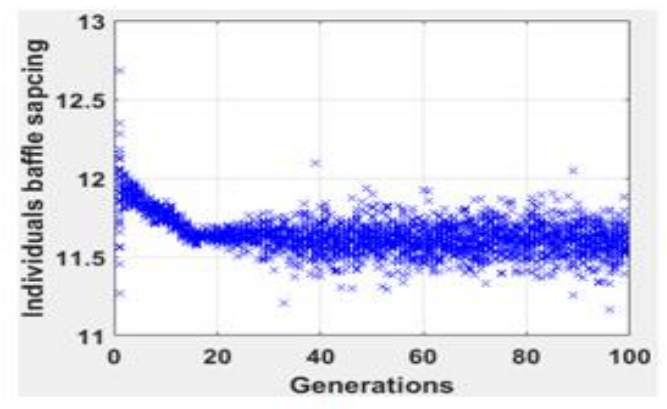

(D)

Figure 2. a) Generation of individuals $\mathrm{mC}$, b) Generation of individual baffle spacing, c) generation of best fitness, d) Generation of individual ds for R134a fluid

\section{V.CONCLUSION}

In this research paper, modified KGMO algorithm is applied to calculate the tube side heat transfer coefficient in the shell side. The parameters considered in the modified KGMO algorithm are heat transfer coefficient $h_{i}$ and correlation factors such as baffle cut $J_{c}$, unequal baffle spacing $J_{s}$, bundle bypass $J_{b}$, laminar flow $J_{r}$, and baffle leakage $J_{l}$. By using modified KGMO algorithm, the enhancement factor $J_{x}$ is effectively increased. The proposed algorithm is evaluated on two dissimilar types of fluids such as R245fa and R134a. The enhancement factor $J_{x}$ of proposed algorithm is 2.8063 for R245fa fluid and 1.9346 for R134a fluid, which is better compared to the existing schemes: Bell-Delaware method [16] andKGMO [21]. The simulation outcomes show a very good agreement with operational data. The optimal design parameter is efficient for simulation of heat transfer coefficients. The thermal efficiency is the important coefficient for improving the electricity generation without increasing the cost.In future work, a new hybrid optimization algorithm is developed for measuring the different parameter settings to improve the efficiency of heat exchanger.

\section{REFERENCES}

1. A.A.A. Arani, and R. Moradi, "Shell and tube heat exchanger optimization using new baffle and tube configuration", Applied Thermal Engineering, vol.157, pp.113736, 2019.

2. H. Azarkish, and M. Rashki, "Reliability and reliability-based sensitivity analysis of shell and tube heat exchangers using Monte Carlo Simulation", Applied Thermal Engineering, vol.159, pp.113842, 2019

3. U. Roy, H.K. Pant, and M. Majumder, "Detection of significant parameters for shell and tube heat exchanger using polynomial neural

4. Z. Said, S.M.A. Rahman, M.E.H. Assad, and A.H. Alami, "Heat transfer enhancement and life cycle analysis of a Shell-and-Tube Heat network approach", Vacuum, 2018.

Exchanger using stable CuO/water nanofluid", Sustainable Energy Technologies and Assessments, vol.31, pp.306-317, 2019.

5. J. Oravec, M. Bakošová, M. Trafczynski, A. Vasičkaninová, A. Mészáros, and M. Markowski, "Robust model predictive control and PID control of shell-and-tube heat exchangers", Energy, vol.159, pp.1-10, 2018.

6. J.J.C. Barros, M.L. Coira, M.P. de la Cruz López, and A. del Caño Gochi, "Sustainability optimisation of shell and tube heat exchanger, using a new integrated methodology", Journal of Cleaner Production, vol.200, pp.552-567, 2018.

7. M. Mirzaei, H. Hajabdollahi, and H. Fadakar, "Multi-objective optimization of shell-and-tube heat exchanger by constructal theory", Applied Thermal Engineering, vol.125, pp.9-19, 2017.

8. D. Yang, T.S. Khan, E. Al-Hajri, Z.H. Ayub, and A.H. Ayub, "Geometric optimization of shell and tube heat exchanger with interstitial twisted tapes outside the tubes applying CFD techniques", Applied Thermal Engineering, vol.152, pp.559-572, 2019.

9. M.O. Petinrin, T. Bello-Ochende, A.A. Dare, and M.O. Oyewola, "Entropy generation minimisation of shell-and-tube heat exchanger in crude oil preheat train using firefly algorithm", Applied Thermal Engineering, vol.145, pp.264-276, 2018.

10. B.C. Du, Y.L. He, Y. Qiu, Q. Liang, and Y.P. Zhou, "Investigation on heat transfer characteristics of molten salt in a shell-and-tube heat exchanger", International Communications in Heat and Mass Transfer, vol.96, pp.61-68, 2018.

11. R.V. Rao, and A. Saroj, "Economic optimization of shell-and-tube heat exchanger using Jaya algorithm with maintenance consideration", Applied Thermal Engineering, vol.116, pp.473-487, 2017.

12. X. Gu, M. Wang, Y. Liu, and S. Wang, "Multi-parameter optimization of shell-and-tube heat exchanger with helical baffles based on entransy theory", Applied Thermal Engineering, vol.130, pp.804-813, 2018.

13. S. Wang, J. Xiao, J. Wang, G. Jian, J. Wen, and Z. Zhang, "Configuration optimization of shell-and-tube heat exchangers with helical baffles using multi-objective genetic algorithm based on fluidstructure interaction", International Communications in Heat and Mass Transfer, vol.85, pp.62-69, 2017.

14. M. Amini, and M. Bazargan, "Two objective optimization in shelland-tube heat exchangers using genetic algorithm", Applied thermal engineering, vol.69, no.1-2, pp.278 285, 2014. 
15. S. Fettaka, J. Thibault, and Y. Gupta, "Design of shell-and-tube heat exchangers using multiobjective optimization", International Journal of Heat and Mass Transfer, vol.60, pp.343-354, 2013.

16. I. Milcheva, F. Heberle and D. Brüggemann, "Modeling and simulation of a shell-and-tube heat exchanger for Organic Rankine Cycle systems with double-segmental baffles by adapting the BellDelaware method", Applied Thermal Engineering, vol.126, pp.507517, 2017.

17. A. Erdogan, C.O. Colpan and D.M. Cakici, "Thermal design and analysis of a shell and tube heat exchanger integrating a geothermal based organic Rankine cycle and parabolic trough solar collectors", Renewable energy, vol.109, pp.372-391, 2017.

18. D. Walraven, B. Laenen and W. D'haeseleer, "Comparison of shelland-tube with plate heat exchangers for the use in low-temperature organic Rankine cycles”, Energyconversion andmanagement, vol.87, pp.227-237, 2014.

19. D. Walraven, B. Laenen and W. D'haeseleer, “Optimum configuration of shell-and-tube heat exchangers for the use in lowtemperature organic Rankine cycles", Energy Conversion andManagement, vol.83, pp.177-187, 2014.

20. S. Lakhani, A. Raul and S.K. Saha, "Dynamic modelling of ORCbased solar thermal power plant integrated with multitube shell and tube latent heat thermal storage system", AppliedThermalEngineering, vol.123, pp.458-470, 2017.

21. T.S. Reddy, T.V.S. Reddy, "Optimization of Shell and Tube Heat Exchanger Design in Organic Rankine Cycle System Using Kinetic Gas Molecule Optimization",International Journal of Intelligent Engineering and Systems, vol.12, no.2, 2019

\section{AUTHORS PROFILE}

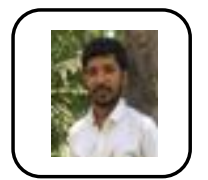

T Subba Reddy.Research scholar at VTU Bachelors Degree from ALIET and Masters Degree from with Specialization in CAD/CAM Engineering and $\mathrm{PhD}$ from University visweswarayya College Bengaluru.

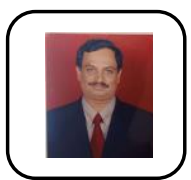

T V Sreerama Reddy Currently working as an professor and HEAD OF THE DEPARTMENT in the department of Mechanical Engineering in Banglore Institute of Technology, Bengaluru. He completed his PhD from VTU. 